\title{
Inclusão sociodigital no contexto UCA Total
}

\author{
Lucila Maria Costi Santarosa $^{1}$, Debora Conforto ${ }^{2}$, Fernanda Chagas Schneider ${ }^{1}$, \\ ${ }^{1}$ Programa de Pós- Graduação em Informática na Educação (PGIE) e ${ }^{1}$ Programa de Pós- \\ Graduação em Educação (PPGEDU) - Universidade Federal do Rio Grande do Sul \\ (UFRGS) - Porto Alegre - RS - Brasil \\ ${ }^{2}$ Secretaria Municipal de Educação (SMED) - Prefeitura de Porto Alegre - Porto Alegre \\ - RS - Brasil \\ lucila.santarosa@terra.com.br, deboraconforto@gmail.com, \\ ferchsc@yahoo.com.br
}

\begin{abstract}
This paper discusses the National Policy of the Inclusive Education Policy and the distribution of Laptops - PROUCA. Both operate under the logic of inclusion in the context of education, the first aiming at school inclusion and the other at digital inclusion. In order to observe how the inclusive process of people with disabilities mediated by laptops occurs, a qualitative descriptive research was performed, focusing on the TOTAL UCA reality in Tiradentes, Minas Gerais. The results of the research project showed that the distribution of laptops, labeling the offered tool under the concept of technological homogeneity and uniformity, imposes barriers to the care for diversity in a socio-digital inclusion scenario
\end{abstract}

Resumo. O presente trabalho aproxima a Politica Nacional de Educação Inclusiva e a Política de distribuição de Laptops - PROUCA. Ambas operam sob a lógica da inclusão em contexto de ensino regular, a primeira visando à inclusão escolar e, a outra, a inclusão digital. Com o objetivo de observar como ocorre o processo inclusivo de pessoas com deficiência mediadas por laptops, realizou-se uma pesquisa qualitativa, descritiva em formato de estudo de caso, enfocando a realidade UCA TOTAL de Tiradentes-MG. Os resultados da pesquisa apontaram que o projeto de disseminação de laptops, balizando a ferramenta ofertada sob o conceito da homogeneidade e uniformidade, impõe barreiras ao atendimento da diversidade em situação de inclusão sociodigital.

\section{Introdução - Inclusão sociodigital no Brasil}

Alinhando-se aos contemporâneos movimentos mundiais de democratização do acesso às tecnologias da informação, o Brasil vem implementando diferentes projetos que visam fomentar a inclusão digital de sua população. Ilustram essas iniciativas o Programa Computadores para Inclusão, o PROINFO e o Programa Nacional de Apoio à Inclusão Digital nas Comunidades - Telecentros.br. 
Mais recentemente, o Brasil passou a buscar um projeto que promovesse movimentos efetivos de inclusão digital, encontrando na iniciativa que prevê o oferecimento de laptops educacionais, a porta de entrada para a inserção de seus estudantes ao mundo tecnológico. Adicionando mobilidade à receita de inclusão digital, o governo propõe a ruptura com o modelo de disponibilização de tecnologias por meio dos laboratórios de informática. Sendo assim, a rigidez e escassez destes ambientes informatizados passa a dar lugar à fluidez de uma tecnologia móvel que independe de tempo e de espaço para sua utilização.

Essa proposta que originalmente é defendida pela ONG - One Laptop per Child ${ }^{1}$ (OLPC), foi adaptada ao contexto brasileiro e rebatizada como Projeto Um Computador por Aluno - PROUCA. Sua implementação no país foi acompanhada por um grupo interministerial que avaliou a viabilidade do projeto em caráter experimental, onde inicialmente se observou a realidade de 5 contextos escolares contempladas com laptops educacionais.

A avaliação dessa ação inicial apontou para uma qualificação do processo de ensino e indicou um incremento nos campos econômico e científico do país. Após a visualização de tais resultados, o governo passou a organizar ações que oportunizassem a continuidade e ampliação do projeto.

Em 2010 iniciou-se a segunda etapa do projeto, quando o governo adquiriu 150.000 laptops educacionais a serem distribuídos para escolas públicas. O Classmate PC, criado pela Intel e desenvolvido nacionalmente pela CCE, foi a tecnologia licitada por apresentar os requisitos educacionais e por ser um laptop de "baixo custo" (cerca de $\mathrm{R} \$ 553$ cada).

Nesta fase, 300 escolas passaram a compor o universo de atuação do projeto. Como critérios de seleção, cada uma delas deveria ter o mínimo de 500 alunos matriculados; possuir energia elétrica e local de armazenamento dos equipamentos; estar preferencialmente próxima a um Núcleo de Tecnologias Educacionais; se manifestar por meio de um termo de adesão, de forma solidária, responsável e comprometida com o projeto, bem como apresentar a anuência do corpo docente.

Além das escolas selecionadas, alguns municípios passaram a ser atendidos em totalidade, ou seja, todas as escolas públicas da localidade receberam laptops para sua rede de ensino. Esses municípios se caracterizam como "Cidades UCA Total", sendo eles: Barra dos Coqueiros/SE, Caetés/PE, Santa Cecília do Pavão/PR, São João da Ponta/PA, Terenos/MS e Tiradentes/MG.

Desta forma, a combinação computadores/escola foi atualizada com o programa PROUCA que, ao conquistar uma nova configuração e ampliação, passou a responder aos desafios colocados pelas contemporâneas Políticas Públicas para a Educação. Aproximar e buscar a complementaridade entre ações governamentais potencializam a concretização das metas estabelecidas para qualificar o processo educacional nas instituições de ensino brasileiras. As Políticas Públicas de respeito e de valorização da

\footnotetext{
${ }^{1}$ A OLPC é uma associação sem fins lucrativos, criada por pesquisadores do Media Lab do MIT (Massachusetts Institute of Technology) em 2001. Foi criada com o intuito proporcionar a disseminação de laptops educacionais a baixo custo.
} 
diferença conquistam novos e importantes recursos para viabilizar estratégias para a construção de uma Educação Inclusiva.

\section{A Política Nacional de Educação Inclusiva}

O Programa de Educação Inclusiva emerge com o propósito de romper com a histórica configuração do processo de escolarização que exclui indivíduos e grupos considerados fora dos padrões homogeneizadores. Formas distintas de exclusão têm marcado o processo educacional, até mesmo pela busca de sua organização em grupos de "iguais". A escola configurada por série ou por ciclos de formação, agrupa aprendizes por perfil cognitivo ou por idade, mudando o critério, mas não alterando o desejo de uma homogeneidade explícita ou, quando muito, de um pluralismo tolerante. $\mathrm{Na}$ sempre difícil relação inclusão/exclusão e nos processos de segregação e de integração, os diferentes critérios de seleção e de agrupamento vêm produzindo e naturalizando o fracasso escolar.

Nesta nova perspectiva, o conceito de diferença assume no sistema educacional brasileiro uma nova construção, pois frequentar a escola regular passa a ser uma garantia legal de todos, independentemente das fragilidades físicas, sensoriais ou cognitivas que, por ventura, o aluno venha a manifestar. Aceitar a diferença deixa de ser uma ação altruísta e passa a ser um direito constitucional.

O discurso pedagógico relativo ao respeito e à valorização da diversidade humana traz consigo, como analisa Charlot (2004,p.24), "a contradição entre o princípio político justo e as consequências pedagógicas de sua aplicação que podem, muitas vezes, ser contrárias a esse princípio". A democratização da educação, a inovação educacional e a flexibilização dos tempos e dos espaços para a escolarização são conceitos que se entrelaçaram no cenário educativo, provocando intensas rupturas no discurso político-pedagógico, mas também, desencadeando dificuldades quanto à implementação de novas práticas educativas.

É assumindo esse desafio que a Secretaria de Educação Continuada, Alfabetização e Diversidade do Ministério de Educação - SECADI/MEC passou a promover ações a fim de assegurar a inclusão de alunos com deficiência, transtornos globais do desenvolvimento e altas habilidades/superdotação no ensino regular, tendo por objetivo o acesso, a permanência, a participação e a aprendizagem desses alunos, orientando os sistemas de ensino a promoverem respostas às deficiências por meio de diferentes diretrizes. Dentre elas, é prevista a oferta de um Atendimento Educacional Especializado (AEE), espaço educacional que deve disponibilizar e organizar recursos que propiciem a participação dos alunos em aula, considerando as especificidades de cada um. Ressalta-se que o AEE não deve substituir as atividades de escolarização, mas sim suplementá-las.

\section{A escola - lugar de encontro de políticas}

De acordo o IBGE (Censo, 2010), 23,9\% da população brasileira apresenta algum tipo de deficiência. Desta forma, temos mais de quarenta e cinco milhões de 
pessoas que se incluem nessa parcela da sociedade. Boa parte deste público apresenta-se em idade escolar e por isso devem ser contemplados pelas ações que visam sua aplicabilidade neste contexto.

Pesquisas no âmbito da informática na educação especial evidenciam a relevância do trabalho com tecnologias no processo de desenvolvimento de pessoas com deficiência, proporcionando a quebra de obstáculos e a transposição de barreiras. Segundo Santarosa e Outros (2010), as TICs abrem portas, amenizando a discriminação social e diminuindo a segregação ao proporcionar que todos possam demonstrar suas capacidades. Propiciam um espaço de oportunidades, principalmente para as pessoas cujos padrões de aprendizagem não seguem os quadros típicos de desenvolvimento.

Relacionando as possibilidades das ações das políticas públicas apresentas neste estudo podemos construir um panorama educacional brasileiro como uma dupla face, por um lado inclusiva e por outro tecnológica. Ambos os temas se entrecruzam quando abordamos questões relacionadas à escola atual. Esta instituição vem sofrendo modificações concomitantes visando abarcar a diversidade dos estudantes e também para responder às políticas que preveem a oferta de laptops para cada aluno vinculado a este contexto.

As ações do Ministério da Educação para concretizar a construção da educação inclusiva e do Ministério da Ciência e Tecnologia com a distribuição dos Laptops educacionais, respondem cada uma delas a uma das faces. A face inclusiva necessita que a face tecnologia disponibilize recursos que impulsionem o processo de desenvolvimento e aprendizagem humana, o que atesta a relevância e a necessária complementaridade destas ações governamentais.

Considerando que a escola brasileira hoje responde a essas demandas inclusivas e tecnológicas, observamos que as ferramentas disponibilizadas através do Projeto UCA podem ajudar a romper com a lógica racionalista excludente, ao permitir que a diversidade seja refletida também no processo de aprendizagem, ao respeitar as especificidades e a história de vida de seus alunos.

\section{Análise dos movimentos inclusivos em uma realidade UCA -Total}

Com o objetivo de observar os movimentos desencadeados no processo de inclusão de alunos com deficiência mediados por laptops do Programa Um Computador por Aluno, enfocamos uma realidade UCA TOTAL por essa compreender a toda rede de ensino de uma localidade e, com isso, aumentarem-se as chances de identificação de alunos com deficiência na rede regular. A escolha da cidade de Tiradentes-MG como lócus de pesquisa deu-se justamente por observarmos um status avançado de implementação do projeto e identificarmos alunos em situações inclusivas na rede de ensino.

Desta forma, iniciou-se uma pesquisa ${ }^{2}$ qualitativa descritiva, em formato de estudo de caso, que teve seis meses de duração (mai/2011 à nov/2011) e contou com

\footnotetext{
${ }^{2}$ Projeto de Pesquisa apoiado pelo Conselho Nacional de Desenvolvimento Científico e Tecnológico (CNPq), através do edital CNPq / CAPES / MEC-SEB No.76/2010 - Projeto n ${ }^{\circ}$ 550374/2011-6
} 
diferentes etapas, onde se analisou aspectos relacionados à gestão municipal de educação, à configuração do contexto escolar, à atuação da direção, do corpo docente e discente e da família do aluno em processo de inclusão sociodigital.

Para tanto, foram realizadas entrevistas semi-estruturadas e grupos focais com os diferentes atores da rede de ensino de Tiradentes-MG. Também foi realizada a análise documental e períodos de observação "in loco", momentos em que foram observadas as realidades de cada uma das 7 escolas deste contexto. Citamos ainda, a criação de uma rede virtual de agentes de observação para coleta de dados. Neste método, o próprio professor regente da classe inclusiva relatou sua realidade diária enfocando os processos de interação/mediação/adaptação dos sujeitos de pesquisa com as tecnologias. Para tanto, fizemos uso do ambiente virtual Eduquito ${ }^{3}$, onde mantivemos o vínculo com o contexto de pesquisa mesmo que remotamente.

Após a fase inicial de identificação das situações inclusivas, delimitou-se o universo de pesquisa que apontou um interessante contexto, onde três distintas professoras eram responsáveis pela inclusão de 9 alunos com diferentes deficiências, sendo eles: 1 sujeito que apresenta deficiência intelectual, 2 sujeitos que apresentam visão subnormal - 1 sujeito com Síndrome de Irlen, 3 sujeitos que apresentam baixa visão e 3 sujeitos que apresentam Transtorno de Déficit de Atenção - TDAH. ${ }^{4}$

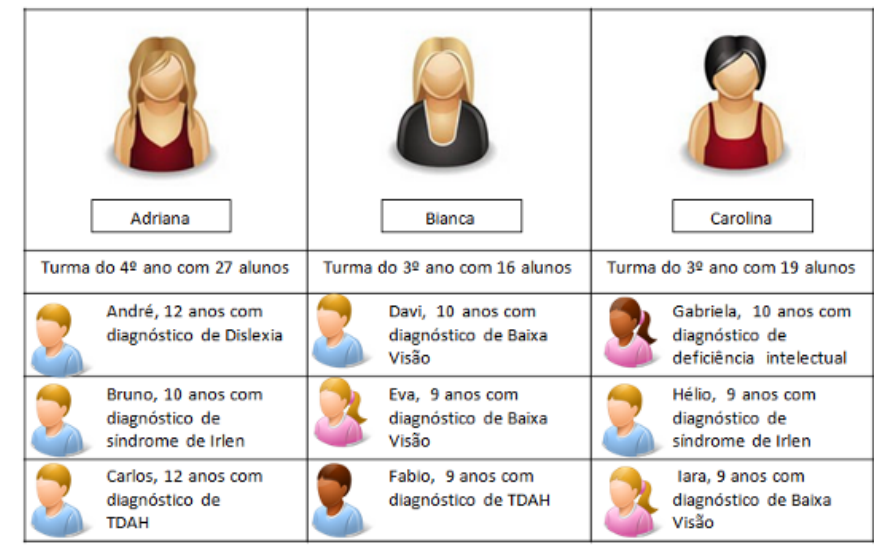

Figura 1 - Quadro de situações inclusivas

Ao analisarmos os dados obtidos precisamos, inicialmente, ampliar o olhar para além das salas de aula onde os sujeitos estavam matriculados, pois, ao notarmos que as ações políticas e as configurações contextuais influenciavam essa realidade, se fez necessário observar a cidade como palco da inclusão social e digital desses alunos, para só depois aproximarmos o olhar do sujeito e dos elementos envolvidos em seu processo inclusivo.

Assim, destacamos que a implementação de projetos de inclusão digital na cidade, vem tornando Tiradentes cada vez mais atuante junto aos fluxos da sociedade globalizada. No entanto, a necessidade de garantir que essa inserção tecnológica não modifique seu contexto arquitetônico histórico acaba impondo limitações referentes às

\footnotetext{
3 Ambiente Virtual de Aprendizagem desenvolvido pelo Núcleo de Informática na Educação Especial NIEE

${ }^{4}$ Todos os sujeitos estão aqui denominados por meio de codinomes
} 
soluções possíveis, fazendo com que a tomada de decisões nem sempre considere a opção mais eficaz, mas sim a que menos cause impacto.

Esse conflito refletiu diretamente na implantação do projeto UCA como o motivo para a descaracterização da totalidade pretendida. Os entraves burocráticos para autorização de modificações arquitetônicas foram apontados como o impeditivo para a maior escola da cidade não ofertar a tecnologia aos seus alunos. Isto fez com que 590 alunos da escola estadual assistissem a tecnologia defasar sem que pudessem interagir com ela.

Essa constante busca pela conservação do ambiente intacto nos faz inferir também que a cidade se manterá como um local inacessível à diversidade humana. $\mathrm{O}$ preocupante é que isso também ecoa na rede de ensino de Tiradentes que, por utilizar prédios do século XVIII, não observa requisitos de acesso às suas dependências, pressuposto básico da política inclusiva vigente.

Por outro lado, destacamos as ações que já acenam para uma configuração de município inclusivo, ao observarmos que o acesso à rede regular de ensino vem sendo oportunizado a todos os alunos. Entretanto, salientamos que a inclusão não depende somente de portas abertas, mas também de diferentes ações que garantam que a criança com deficiência participe de todos os movimentos escolares. Como em Tiradentes a tecnologia permeia o ambiente educativo, esse se torna mais um requisito a ser observado no processo inclusivo, que assume aqui um cunho tanto social quanto digital. Ao enfocarmos a realidade pesquisada, observamos que para os nove sujeitos pesquisados o processo de inclusão sociodigital assumiu diferentes configurações.

Além de frequentarem a escola regular dois sujeitos já se encontram em situação de dupla matrícula e outros três já contaram com esse suporte. No entanto, os quatro restantes nem mesmo contam com o apoio pedagógico escolar, carecendo de maior atenção dos gestores municipais no que tange a oferta de atendimentos especializados que contribuam com a escolarização desse público.

Nos casos em que não há atenção extraclasse o processo inclusivo recai sob a responsabilidade das professoras, que têm a incumbência de articular ações com os outros atores envolvidos e fazer com que suas práticas contemplem as necessidades dos alunos com deficiência. Cabe salientar que nessa pesquisa identificamos que apenas 4 das 9 famílias atuam no processo de escolarização dos alunos. Ocupadas com o provimento do sustento, acabam por terceirizar a educação dos filhos e deixar esta a cargo da escola, reforçando a responsabilidade do professor sobre os alunos.

Assim, nos deparamos com outra fragilidade que surge da brecha que existe na formação de professores. Estes saem dos cursos de graduação tendo apenas contato superficial com a temática da educação especial e, ao se depararem com situações que requerem tais conhecimentos, são induzidos a práticas intuitivas, sem embasamento teórico. A exceção de uma única professora, que pontua ter construído conhecimentos em seus anos de magistério e que realmente se dedica a realizar ações que abarquem a diversidade, as professoras percebem-se despreparadas para trabalhar com alunos com deficiências, ainda mais em situação onde devem mediar o uso de tecnologias.

A fragilidade nos processos de formação inicial e continuada dos professores para o atendimento de sujeitos com deficiências dificulta a construção de interfaces 
tecnológicas para promover práticas de inclusão sociodigital. O desconhecimento das possibilidades das tecnologias em operar como interfaces de cidadania para a diversidade humana e a concepção de um sujeito forjado no paradigma deficitário têm colocado o público-alvo da Educação Especial na exterioridade dos processos de apropriação tecnológica e, com isso, das possibilidades de inserção sociodigital.

Todas as três professoras desconhecem as contribuições que o campo da Tecnologia Assistiva pode ofertar, expondo seus alunos a um uso do laptop em sua configuração normal. Contudo, é preciso salientar que raras seriam as adaptações possíveis no laptop ofertado. Por ser vinculado ao software Metasys, criado sob a lógica Gnu/Linux baseada em Fedora, acaba não dispondo de muitos recursos, por ser esta uma distribuição Linux com uma comunidade de desenvolvimento pouco difundida.

Dessa forma, identificamos que a tecnologia licitada mostra alguns impeditivos ao processo de inclusão sociodigital do público especial.

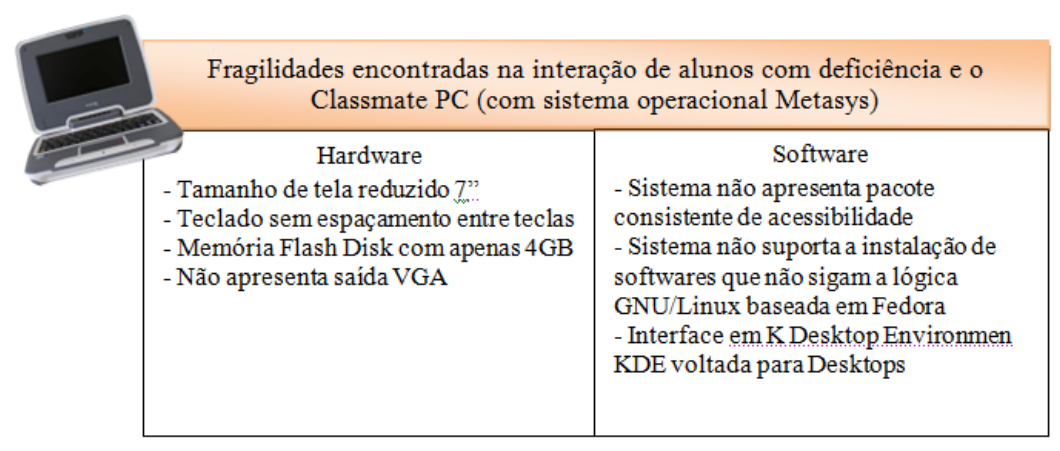

\section{Figura 2 - Fragilidades da Tecnologia}

O laptop não tem um pacote consistente de acessibilidade, não suportando também a instalação dos softwares mais populares dessa natureza. O tamanho reduzido da tela e do teclado se mostram como fatores que dificultam a interação de alunos com deficiências visuais. Além disso, a inexistência de uma saída VGA dificulta a associação do laptop a uma tela externa de maiores proporções que possibilitaria uma melhor visualização dos conteúdos.

Pudemos identificar que para um dos alunos com TDAH a interface KDE, desenvolvida para desktops, se mostra como um sistema que apresenta sobrecarga cognitiva, fazendo com que o aluno dispense mais atenção ao aprendizado das funcionalidades do que ao conteúdo propriamente dito. Ainda foi identificada que a pouca memória disponível no laptop prejudica a sua utilização por um dos alunos, não por sua deficiência, mas sim por ser um usuário frequente que, por não dispor de internet em casa, necessita salvar todos os arquivos necessários em seu equipamento.

Diante dos expostos, podemos afirmar que para crianças com deficiências mais ligadas a déficits cognitivos, a ferramenta licitada se aproxima mais de algo que somente auxilia seu processo inclusivo sem apresentar grandes barreiras. Entretanto, para os alunos que apresentam deficiências físicas, como os com deficiências visuais, a configuração diminuta se mostra como um fator dificultador.

É necessário observarmos que o uso do laptop em Tiradentes ainda perpassa pela autoridade do professor, sendo esse o promotor de seu uso ou o responsável pelo 
descarte. Durante o período dessa pesquisa, pudemos observar que a percepção do docente sobre a tecnologia refletia diretamente em sua oferta dentro de sala de aula.

As professoras familiarizadas com as potencialidades do equipamento 0 entendiam como um agente agregador, propondo um uso frequente e didático da tecnologia. Já a professora que até pouco tempo desconhecia a ferramenta, tendia a enxergá-la como apenas mais uma atribuição, não vendo sentido em seu uso e assim promovia uma utilização esporádica e de cunho recreativo.

Mesmo nessa realidade onde o computador é utilizado para o entretenimento, inferimos que a tecnologia contribui para o desenvolvimento cognitivo dos sujeitos, uma vez que estes passam a se apropriar das funcionalidades do recurso. Contudo, podemos observar uma otimização das possibilidades pedagógicas da ferramenta somente nas realidades mediadas pelas professoras que percebem a tecnologia como contributiva, onde o laptop passou a ser o meio para novos aprendizados.

Nesse processo, observamos que a turma desempenha um importante papel na relação aluno-laptop. Podemos dizer que a descoberta de algo interessante era anunciada para que pudesse ser repicada. Dessa forma, a troca de saberes acontecia de forma corriqueira, sem que necessitasse de solicitações ou incentivos. Nesse contexto, os alunos com deficiência, de maneira geral, eram mediados por colegas que apontavam caminhos ou realizavam os passos até que se completasse uma tarefa. Por vezes, também podíamos perceber que alguns dos próprios sujeitos de pesquisa assumiam a postura de mediadores e compartilhavam seus saberes com o restante da turma.

Visualizamos nisso uma face do projeto que gera a possibilidade de permitir que o sujeito seja mais autônomo no processo de aprendizagem, desde que mediado para se apropriar de suas funcionalidades e autorizado a utilizar o recurso. No entanto, o controle exercido pelo professor só não se faz presente em uma das turmas, onde a proposta de uso se aproxima muito com a do projeto idealizado, quando o laptop fica à disposição do aluno a qualquer momento. Já nas outras duas a utilização da ferramenta dentro e fora da escola ainda perpassa pelo aval do docente.

Cabe aqui trazermos as contribuições de Conforto (2006) que ao analisar a transformação da escola do hardware para a escola do software, observou que no uso do laboratório de informática os sujeitos dependiam da relação tempo e espaço para realizarem atividades com as tecnologias. Por ser esse um ambiente físico partilhado entre toda uma realidade escolar, a grade de horários regia as variáveis "quando" e "quem" faria uso dos equipamentos. Nessa configuração, existia ainda a figura do monitor de informática que, responsável pelo laboratório, exercia o controle dessas variáveis, além de ter o poder de bloquear o acesso a certos conteúdos.

Observamos que nessas realidades, a mobilidade e a disponibilidade trazidas pelos laptops ainda não foram suficientes para que se transcendesse o antigo modelo de controle do uso das tecnologias. Tendo a única mudança vinculada à extinção do cargo do monitor de informática, exercido agora pelo professor.

\section{Considerações Finais}

Os diferentes resultados desse estudo apontam para uma Tiradentes engajada com a proposta de disseminação de laptops, a exceção da escola estadual, e disposta a 
atender aos preceitos da Política Nacional de Educação Especial na Perspectiva da Educação Inclusiva. No entanto, essa pesquisa que buscou observar os movimentos desencadeados no processo de inclusão de alunos com deficiência mediados por laptops do Programa Um Computador por Aluno-UCA, nos permite afirmar que o cenário estudado reflete uma fragilidade que aponta para o desconhecimento. Ao formular o projeto, seus idealizadores apresentaram uma proposta de grande importância para que o Brasil ocupe um lugar de vanguarda da educação. No entanto, os processos burocráticos de aquisição de tecnologias combinados ao desconhecimento de uma política que situa a diversidade no contexto de ensino regular, resultaram em uma proposta que pouco abarca alunos com deficiência.

Historicamente, consideramos os indivíduos que fogem do padrão homogêneo somente em um segundo momento e não foi diferente com o PROUCA. Os resultados da pesquisa apontaram que o projeto de disseminação de laptops do governo federal, balizando a ferramenta ofertada sob o conceito da homogeneidade e uniformidade tecnológica, fragiliza o atendimento da diversidade. O Classmate PC, consorciado ao sistema operacional Metasys, resulta em uma solução fechada que não atende a maioria dos requisitos de acessibilidade, impedindo também que softwares e hardwares que contemplem esse aspecto sejam instalados no equipamento.

No entanto, mesmo encontrando dificuldades de acesso, a forte motivação dos alunos com deficiência aponta o uso da tecnologia como fator positivo no contexto escolar. Salientamos que, em algumas realidades, a presença do laptop foi capaz de promover trocas entre os alunos, onde os sujeitos de pesquisa foram mediados e mediadores do processo de apropriação uns dos outros. Mas, em outras realidades, o controle exercido pelo professor por vezes bloqueou esse aspecto do projeto. Sobre isso Lévy (1992) aponta que a incursão da escola no mundo tecnológico se dá de forma turbulenta, também em função do papel centralizador do professor, pois há mais de cinco mil anos essa instituição vem se baseando no falar/ditar do mestre e a inclusão de tecnologias nesse contexto requerem o abandono de um hábito antropológico.

Velhas práticas que reafirmam o papel central do docente deverão ser revistas em realidades permeadas pelas tecnologias. Conforme Santarosa e outros (2010), a burocratização do conteúdo escolar se mostra frágil, no momento em que observamos que o que deve ser aprendido não pode mais ser programado ou definido por um currículo métrico. Somente quando forem enfocadas as aprendizagens e não mais os programas, poderemos perceber a ação educacional se deslocar do plano individual para o plano coletivo, partir da homogeneidade para a heterogeneidade e, somente ai estaremos contemplando a diversidade em nossos movimentos de inclusão sociodigital.

Esses movimentos ainda dependem de uma série de outros fatores para que se efetivem. Em Tiradentes, pudemos perceber que o despreparo para atender a diversidade em contexto escolar regular é ainda demarcado pela desatenção ao acesso arquitetônico, pela restrição ao atendimento educacional especializado e pelo escasso apoio pedagógico ao professor.

Sendo assim, a prática inclusiva na cidade de Tiradentes garante a vinculação do aluno especial à rede regular, mas não articula movimentos capazes de promover sua efetiva inclusão, deixando essa, quase que exclusivamente, a cargo dos docentes que, em grande maioria, não se sentem preparados para atuarem junto a essa realidade. 
Cabe salientarmos que avaliamos como uma evolução estarmos discutindo hoje questões relacionadas a esse tema, se observarmos que não há muito tempo atrás a sociedade descartava ou segregava o público alvo da educação especial de seus fluxos. Dessa forma, desfamiliarizados com a presença da diversidade humana, ainda geramos ações que não consideram como premissas suas necessidades, mesmo que hoje a inclusão seja um direito reafirmado por lei.

Equacionar as diferentes variáveis que compõe a realidade de ensino brasileira e contemplá-las nas diversas políticas públicas projetadas para garantir maior qualidade na educação não é tarefa fácil. No entanto, é preciso ter presente que pensar em todos não significa pensar em cada um. Ao não considerar os sujeitos com deficiências e suas especificidades em projetos que visem sua aplicabilidade no contexto de ensino regular torna esse processo um simples ingresso, não permitindo que tais alunos façam realmente parte dos movimentos de formação e socialização previstos no ambiente escolar.

Suscitamos como grande contribuição deste estudo a visibilidade dada à frágil articulação entre políticas educacionais. Ações governamentais forjadas pelo MEC desconhecem as metas projetadas e, principalmente, desconsideram os contextos socioculturais em que serão aplicadas. O PROUCA, que traz em seu cerne a possibilidade de individualizar o uso da tecnologia, disponibiliza para o aluno com deficiência uma tecnologia que inviabiliza a customização as suas especificidades sensoriais e cognitivas.

Mesmo com a incerteza de futuro do Projeto Um Computador por Aluno, os resultados desta pesquisa, ao mesmo tempo em que indicam a premência de que ações governamentais evidenciem uma forte articulação, subsidiam futuras tomadas de decisão que venham envolver a aproximação de recursos tecnológicos e a contemporânea configuração dos sistemas regulares de ensino com a presença da diversidade humana.

\section{Referências}

IBGE - Censo Demográfico 2010 - Resultados Preliminares da Amostra http://deficientefisico.com/resultados-do-censo-2010-feito-pelo-ibge-sobre-pessoascom-deficiencia - Acessado em 15/09/2013.

CHARLOT, B Projeto político e projeto pedagógico. In: MOLL, Jaqueline (Org). Ciclos na escola, tempos na vida: criando possibilidades. Porto Alegre: Artmed, 2004.

CONFORTO, D. Da escola do hardware para a escola do software: o processo educativo sob a lógica da compressão do tempo e do espaço, UFRGS, 2006.

LÉVY, Pierre. As Tecnologias da Inteligência o futuro do pensamento na era da informática. 1. ed. Lisboa: Instituto Piaget, 1992.

SANTAROSA, L.M.C. (Org). Tecnologias Digitais Acessíveis - Porto Alegre, JSM, 2010. 